\title{
Public Health Policies and Economic Growth: Experience of the WAEMU and the CAEMC Countries
}

\author{
Tito Nestor Tiehi, Hypolite Konan \\ Economics Department, University of Cocody, Abidjan, Côte d'Ivoire \\ Email: titotiehi@gmail.com
}

How to cite this paper: Tiehi, T.N. and Konan, H. (2017) Public Health Policies and Economic Growth: Experience of the WAEMU and the CAEMC Countries. Modern Economy, 8, 1328-1339. https://doi.org/10.4236/me.2017.811089

Received: October 2, 2017

Accepted: November 13, 2017

Published: November 16, 2017

Copyright (c) 2017 by authors and Scientific Research Publishing Inc. This work is licensed under the Creative Commons Attribution International License (CC BY 4.0).

http://creativecommons.org/licenses/by/4.0/

\section{(c) (i) Open Access}

\begin{abstract}
Purpose of this study is to analyze the implications of public health policies on economic growth in Sub-Saharan African Countries. From the experience of quite two homogeneous Economic Areas, namely the CAEMC and the WAEMU, we will check up the following hypotheses: The trade-off between Public expenditures in health and Economic growth is positive (ii). The income elasticity in the WAEMU Area is higher than that of the CEMAC Zone. Our method is based on the Panel data technique to compare countries from the CAEMC Area and those from the WAEMU zone on the 1995-2013 periods. It leads to the two following outcomes: On one hand, there is a long run relationship between Government health expenditures and economic growth; on the other hand, the income elasticity in the WAEMU is higher.
\end{abstract}

\section{Keywords}

Government Expenditures, Health, Economic Growth, Panel Data, CAEMC, WAEMU

\section{Introduction}

The World Population Health has been improved in a spectacular way over the last decades. Although these improvements have been brought about by a series of factors (hike in incomes and Medical techniques progress, etc.), the increase of health expenditure has much contributed to these factors.

Meanwhile, this evolution of public health spending has become an issue for the relevant states budgets. In fact, in Developing Countries, government health expenditures compete with other development priorities such as education and infrastructures. Surprisingly, in those countries, leaders are rather invited to 
raise the part of their budget that is allocated to the health sector in order to enhance their economic growth [1]. This standpoint of the World Health Organization is justified through the fact that a rise of health investment would reduce yearly additional incomes that could be used for the amelioration of millions of people living conditions and of social infrastructures in poor countries.

Besides, empirical working papers revealed the existence of a correlation between health and growth that is assumed to be positive and bi-directional [2] [3]. This trade-off between health and economic growth was the subject matter of several empirical investigations. In fact, works, such as those of Newhouse [4], Leu [5], Hitiris and Posnett [6], Hansen and King [7], studied the impact of income on health and showed that the level of income helps explain significantly differences in health states. Since the research of Barro [8] and Barro and Sala-i-Martin [9], many studies have equally examined the positive effects of health on economic development. In the same trend, Fogel [10] indicated that $30 \%$ of the British growth over the last two centuries could be accounted for by the improvement of nourishment. Furthermore, Barro [11] shows that a $10 \%$ rise in life expectation entails a $0.4 \%$ increase in economic growth.

Sub-Saharan Africa is the less developed region in the world with its derived woes. Transmitted diseases such as malaria, tuberculosis, HIV AIDS, and infant mortality due to avoidable causes are more frequent than any other regions [12]. Africa is also the region where a great number of women who died from complications during pregnancy are recorded [12].

The WAEMU and CAEMC areas are made of fourteen (14) countries located in Sub-Saharan Africa: height (08) countries in the WAEMU (Benin, Burkina Faso, Côte d'Ivoire, Guinea-Bissau, Mali, Niger, Senegal and Togo), and six (06) in the CAEMU (Cameroon, Central African Republic, Chad, Congo, EquatorialGuinea and Gabon). However, those economic and monetary unions are shaken by recurrent sociopolitical instability that weakens their economy's fundamentals. Nonetheless, the WAEMU and the CAEMC constitute nowadays two vast markets respectively with more than 103 million and 46 million inhabitants.

The GDP/per capita is estimated to be more than US \$ 46 million for the WAEMU Area Versus US \$ 8413 for the CAEMC one [13]. Due to this economic potential and the ever-increasing people's concerns, the stake of this thinking is found in the capacity to investigate a positive and sustainable economic growth that is favored by a prioritization of investments in health.

In this paper, we are going to analyze and compare the impact of health investment on the economic growth of the CAEMC and WAEMU countries, in order to make economic policy recommendations. In spite of all the efforts to improve people's health condition, health indicators remain poor and the economic growth of the CFA area countries is erratic and weak. It is then appropriate for us to show interest on the implication of this rise in health government spending on economic growth in those countries of the WAEMU and CAEMC areas.

This study also proposes: 1) to analyze the effects of economic growth change 
on health government spending; 2) to determine and compare the income elasticity of the CAEMC with that of WAEMU. Two hypotheses are considered, namely: 1) there is a positive trade-off between economic growth and health public expenditures; 2) the income elasticity in the WAEMU Area is higher than that of the CAEMC.

We will unveil the methodology on which this work is founded and we will later analyze the results before deriving a conclusion.

\section{Methodological Approach}

\subsection{The Model}

This study's data are derived from the World Bank's statistics (World Development Indicators). The analysis covers the 1995-2013 period $(T=19)$ and takes account of the set of the CAEMC and WAEMU fourteen (14) countries, thereby displaying a panel of 266 observations.

The model used in this study is inspired from the one developed by Baltagi and Moscone [14] in order to analyze health according to the Income and certain non-monetary determinants. On a specific basis, in this study the dependent variable pheh $_{i t}$ is regressed according to the following model:

$$
\text { pheh }_{i t}=\alpha_{i}+d_{t}+\beta_{1} g d p h_{i t}+\beta_{2} \operatorname{lexp}_{i t}+\beta_{3} e d r_{i t}+\beta_{4} y d r_{i t}+\mu_{i t}
$$

pheh $_{i t}=$ Public health expenditure per capita in country $i$ for year $t$, i.e. the share of GDP that the State allocates to the health sector. This index capture the engagement of government in health sector i.e. the public health policies.

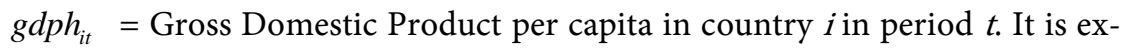
pressed in purchasing power parity (PPP) and in US dollar terms. This indicator provides information on the level of economic performance of the country concerned

$\operatorname{lexp}_{\text {it }}=$ Life expectancy at birth in country $i$ in period $t$, to reflect the quality of life in the country or performance of public health policies.

$e d r_{i t}=$ Dependency ratio of the elderly: that is, the ratio of the population aged 65 years and over to the labor force

$y d r_{i t}=$ Young people's dependency ratio, which is the ratio of the population aged fewer than 15 to the labor force

$\mu_{i t}, \alpha_{i}$ and $d_{t}$ are respectively: Error term, Individual country-specific effect and dummy variable.

Suppose $X_{i t}$ the matrix of explanatory variables. All variables are expressed in logarithm. We then obtain:

$$
\text { Lpheh }_{i t}=\alpha_{i}+d_{t}+\beta_{i}^{\prime} X_{i t}+\mu_{i t}
$$

with, $i=1, \cdots, N ; t=1, \cdots, T$

Following the approach of Baltagi and Moscone [14], we consider in this model two alternatives by integrating the dependence of the observations in cross section. On the first hand, it is assumed that the errors have a multifactorial structure: 


$$
\mu_{i t}=\alpha_{i}+d_{t}+\gamma_{i}^{\prime} f_{t}+\varepsilon_{i t}
$$

where, $f_{t}$ represents a vector of unobserved common effects and, $\varepsilon_{i t}$ the error specific to each country following an $\varepsilon_{i t}$ independent distribution. From Equation (2), the correlation appears because the effect of common externalities or perturbations is similar but not identical across countries. In addition, we hypothesized that common factors introduce a correlation between pairs of statistical units that do not depend on how close they are in geographical space. In Equation (1), we assume that $X_{i t}$ unobserved effects $f_{t}$ are correlated. So, common factors have an impact on health spending not only directly via the structure of the factors, but also indirectly by affecting explanatory variables.

On the second hand, we consider that error term follows the spatial autoregressive process; so:

$$
\mu_{i t}=\delta \bar{\mu}_{i t}+\varepsilon_{i t}
$$

where, $\bar{\mu}_{i t}=\sum_{j=1}^{N} S_{i t} \mu_{i t}$ and $S_{i t}$ representing the term of the $(i, j)$ element of the square weight matrix $(S) \quad N \times N$.

In this study, we adopt weights based on the inverse of the distance between countries [15] [16] [17], and the existence of concentrated forms of highly localized disease [18] [19] [20] [21] [22].

Thus, for both the heterogeneity of the parameters and the cross-sectional dependence of the observations, Baltagi and Moscone [15] used a method developed by Pesaran [23] to estimate and test the equation) with multifactorial errors (Equation (2)). This method is based on correlated common effects (CECs).

$$
\text { Lpheh }_{i t}=\alpha_{i}+d_{t}+\beta_{i}^{\prime} X_{i t}+g_{i}^{\prime} \bar{Z}_{t}+\mu_{i t}
$$

where, $\bar{Z}_{t}=\left(\overline{p h e h}_{t}, \bar{X}_{t}^{\prime}\right)^{\prime}$ with $\overline{p h e h}_{t}$ and $\bar{X}_{t}^{\prime}$ are respectively the mean of the dependent variable and the explanatory variables. The heterogeneity is captured by the individual specific effect $\alpha_{i}$, the dummy variable $d_{t}$ and the charges carried by $g_{i}^{\prime}$.

\subsection{Methods}

\subsubsection{Testing the Dependence}

Table 1 presents the Pesaran test of cross-sectional dependence at level and first difference. The Pesaran CD statistic is based on the average of the correlation coefficients between the different countries taken in pairs for each period of time.

The results indicate cross-country correlation for all variables in the WAEMU and the CAEMC. However, the assumption of independence cannot be rejected as the first difference for most variables in all countries. Indeed, the dependence observed is of a weak nature [24]. This is a consequence of a highly unstable socio-political situation in the countries of the CFA zone (WAEMU and CAEMC), with adverse health consequences. 
Table 1. Cross-section dependence of variables in level and first difference.

\begin{tabular}{|c|c|c|c|c|c|}
\hline \multirow{2}{*}{ Variables } & \multicolumn{3}{|c|}{ WAEMU } & \multicolumn{2}{|r|}{ CAEMC } \\
\hline & Coefficient & $\bar{\rho}$ & Statistics $\mathrm{CD}_{\mathrm{LM}}$ & coefficient & statistics $\mathrm{CD}_{\mathrm{LM}}$ \\
\hline pheh $_{\text {it }}$ & 0.319 & & $7.350^{*}$ & 0.190 & $3.210^{*}$ \\
\hline$g d p h_{i t}$ & 0.141 & & $3.240^{*}$ & 0.250 & $4.220^{*}$ \\
\hline $\operatorname{lexp}_{i t}$ & 0.860 & & $19.830^{*}$ & 0.921 & $15.550^{*}$ \\
\hline$y d r_{i t}$ & 0.169 & & $3.900^{*}$ & 0.367 & $6.200^{*}$ \\
\hline$e d r_{i t}$ & 0.156 & & $3.600^{*}$ & 0.978 & $16.500^{*}$ \\
\hline$\Delta p h e h_{i t}$ & -0.009 & & -0.210 & -0.047 & -0.790 \\
\hline$\Delta g d p h_{i t}$ & 0.084 & & $1.940^{*}$ & 0.010 & 0.170 \\
\hline$\Delta \operatorname{lexp}_{i t}$ & 0.515 & & $11.880^{*}$ & 0.954 & $16.110^{*}$ \\
\hline$\Delta y d r_{i t}$ & 0.051 & & 1.170 & 0.043 & 0.730 \\
\hline$\Delta e d r_{i t}$ & 0.400 & & $9.220^{*}$ & 0.421 & $7.100^{*}$ \\
\hline
\end{tabular}

Note: $\left({ }^{*}\right)$ Rejection of the null hypothesis of independence at the threshold $\alpha=5 \%$.

This result is consistent with the one of Audibert et al. [25], behind that when a country's socio-political situation is chaotic; the government may need to reduce health grants to redirect to areas where the political benefit is higher. However, the period 1995-2013 has been characterized by a significant number of conflicts, with medium or high intensity, of political and military unrest in Guinea-Bissau, Côte d'Ivoire, Niger, and Central African Republic. This would undoubtedly explain the strong disturbances observed in the evolution of income and public health expenditure in the different countries of each monetary union.

\subsubsection{Unit Root Tests}

First, we use the IPS test [26] and the Breitung t-test [27]. These tests are based on assumptions on the cross-sectional independence of the observations. Then we made second-generation test: Cross Sectionally Augmented Dickey-Fuller (CADF statistic). This test, as first-generation (IPS and t-test Breitung) assumes heterogeneity parameters.

Table 2 presents the results of the statistics $W_{t \text {-bar }}$ and the Breitung test for all variables in level and first difference in the WAEMU and in the CAEMC. In the WAEMU, IPS test level results indicate that most of the variables are nonstationary when adding a constant only to the model so that they are all stationary, when the unit root test is applied to their first differences. On the other hand, the Breitung level test does not reject the null hypothesis for all variables when adding a constant. In the CAEMC, the results of the IPS test, (at level and difference) show that most variables are non-stationary. Moreover, the results of the Breitung t-statistic (at level) do not reject the null hypothesis of unit root for all variables when we add a constant.

Table 3 shows the results of the statistical CADF for other delays $\mathrm{P}=0,1,2,3$. 
Table 2. Unit root test Im pesaran shin (IPS, 2003) and breitung.

\begin{tabular}{|c|c|c|c|c|c|c|c|c|}
\hline & \multicolumn{4}{|c|}{ WAEMU } & \multicolumn{4}{|c|}{ CAEMC } \\
\hline & IPS & $W_{t-\text { bar }}$ & Breitung & g t-stat & IPS & $W_{t-b a r}$ & Breitun & g t-stat \\
\hline & Constante & Tendance & Constante & Tendance & Constante & Tendance & Constante & Tendance \\
\hline pheh $_{i t}$ & 0.577 & -0.213 & 0.275 & -0.892 & -1.618 & -0.541 & -0.134 & -0.986 \\
\hline$g d p h_{i t}$ & 0.025 & 1.533 & 1.972 & 1.834 & -0.031 & 0.743 & 0.848 & 1.976 \\
\hline $\operatorname{lexp}_{i t}$ & $-9.003^{*}$ & $-43.281^{\star}$ & $-3.848^{*}$ & 4.498 & $-16.965^{\star}$ & $-37.189^{\star}$ & $-7.103^{*}$ & 3.373 \\
\hline$y d r_{i t}$ & $-2.261^{*}$ & $-6.521^{\star}$ & $-4.066^{*}$ & 2.923 & $-8.123^{*}$ & 0.041 & $-5.169^{*}$ & 4.676 \\
\hline$e d r_{i t}$ & -0.365 & -1.422 & $-3.315^{\star}$ & 1.215 & $-3.557^{\star}$ & 3.057 & $-5.800^{*}$ & 5.220 \\
\hline$\Delta$ pheh $_{i t}$ & $-8.902^{*}$ & $-7.387^{\star}$ & $-4.415^{\star}$ & $-3.771^{*}$ & $-7.115^{\star}$ & $-6.270^{*}$ & $-4.013^{*}$ & $-3.306^{\star}$ \\
\hline$\Delta g d p h_{i t}$ & $-8.073^{*}$ & $-6.970^{*}$ & $-2.923^{*}$ & -1.376 & $-3.208^{*}$ & $-3.295^{\star}$ & $-3.030^{*}$ & 0.989 \\
\hline$\Delta \operatorname{lexp}_{i t}$ & $-6.516^{*}$ & $-24.763^{\star}$ & -0.091 & 3.142 & $-3.903^{*}$ & 3.830 & 0.069 & 4.803 \\
\hline$\Delta y d r_{i t}$ & 0.142 & $-10.796^{*}$ & 0.441 & 4.040 & 2.313 & $-5.471^{\star}$ & 0.299 & 4.885 \\
\hline$\Delta e d r_{i t}$ & 1.481 & $-10.450^{*}$ & 1.783 & 3.391 & 1.268 & $-1.815^{\star}$ & -1.490 & 6.667 \\
\hline
\end{tabular}

Note: $\left.{ }^{*}\right)$ Rejection of the null hypothesis of independence at the threshold $\alpha=5 \%$.

Overall, when the model includes a trend or a constant, all variables at level are non-stationary for delays of Order 0 and 2 in the WAEMU and for delays of order 2 and 3 in the CAEMC. These results are more reliable because they take into account the dependence between countries.

\section{Discussion}

This section presents the results of the study and the comments they provide. To check the statistical properties of the variables, tests for the panel time series were made. These include cross-sectional dependency, unit root, income-elasticity, and cointegration tests.

\subsection{Test of Sensitivity}

To test the sensitivity of our unit root panel results, we perform again CADF statistical eliminating tower in turn one country at a time of the sample. Table 4 reports the CADF statistics for variables $p h e h_{i t}$ and $g d p h_{i t}$. The choice of these two variables is explained by the importance of income as a major determinant in health expenditure.

\subsection{Income Elasticity}

Table 5 presents the Fixed Effect Estimators and Common Correlated Effects Mean Pooled (CCEP) respectively in the WAEMU and the CAEMC area. When time is taken into account, the FE estimate of income elasticity decreases, but remains greater than one (1.989 in WAEMU versus 1.023 in CAEMC). Thus, an increase in GDP in these countries leads to a more than proportional increase in public health investment. Specifically, an increase of $1 \%$ of GDP would increase 
Table 3. Results of the unit root test.

\begin{tabular}{|c|c|c|c|c|c|c|c|c|}
\hline & \multicolumn{8}{|c|}{ CADF } \\
\hline & \multicolumn{4}{|c|}{ WAEMU } & \multicolumn{4}{|c|}{ CAEMC } \\
\hline & \multicolumn{4}{|c|}{ Number of delay } & \multicolumn{4}{|c|}{ Number of delay } \\
\hline & 0 & 1 & 2 & 3 & 0 & 1 & 2 & 3 \\
\hline & \multicolumn{8}{|c|}{ Constante } \\
\hline pheh $_{i t}$ & -1.674 & -1.497 & -1.235 & -1.680 & -2.159 & -1.933 & -1.869 & -1.518 \\
\hline$g d p h_{i t}$ & -1.387 & -1.569 & -1.638 & -1.207 & -1.048 & -1.586 & -0.847 & -1.298 \\
\hline $\operatorname{lexp}_{i t}$ & -0.567 & $-2.668^{\star}$ & -2.047 & $-3.666^{*}$ & -1.831 & -1.729 & -2.327 & $-2.836^{*}$ \\
\hline$y d r_{i t}$ & -0.805 & $-2.359^{\star}$ & -1.409 & -2.312 & -0.656 & $-3.257^{\star}$ & -1.166 & -0.661 \\
\hline$e d r_{i t}$ & -0.578 & $-3.333^{*}$ & -1.231 & -1.669 & $-2.601^{\star}$ & $-3.859^{\star}$ & -1.187 & -0.769 \\
\hline$\Delta p h e h_{i t}$ & $-4.260^{\star}$ & $-2.971^{\star}$ & -2.022 & $-2.482^{*}$ & $-3.543^{\star}$ & $-2.621^{\star}$ & -1.880 & -1.428 \\
\hline$\Delta g d p h_{i t}$ & $-3.873^{\star}$ & $-3.074^{\star}$ & $-2.351^{*}$ & -1.527 & -1.816 & -1.214 & -1.227 & -0.520 \\
\hline$\Delta \operatorname{lexp}_{i t}$ & $-4.852^{\star}$ & -2.282 & $-3.565^{\star}$ & $-3.133^{*}$ & $-3.537^{\star}$ & -2.310 & -1.544 & -1.017 \\
\hline$\Delta y d r_{i t}$ & -0.578 & $-3.243^{*}$ & -0.828 & -1.684 & $-2.505^{\star}$ & -1.505 & -1.238 & -0.591 \\
\hline \multirow[t]{2}{*}{$\Delta e d r_{i t}$} & -1.638 & $-2.348^{\star}$ & $-3.077^{\star}$ & -2.130 & -1.771 & $-2.838^{*}$ & $-2.791^{\star}$ & -1.932 \\
\hline & \multicolumn{8}{|c|}{ Constante and trend } \\
\hline pheh $_{i t}$ & -2.216 & -1.813 & -1.565 & -2.110 & -2.163 & -1.921 & -1.574 & -1.397 \\
\hline$g d p h_{i t}$ & -2.286 & -2.755 & -2.098 & -1.082 & -0.654 & -1.229 & -0.534 & -0.698 \\
\hline $\operatorname{lexp}_{i t}$ & -2.795 & $-3.522^{\star}$ & -2.678 & -2.192 & $-3.116^{*}$ & -1.768 & -1.927 & -2.226 \\
\hline$y d r_{i t}$ & -0.708 & $-3.308^{\star}$ & -2.024 & $-2.990^{*}$ & 0.404 & $-3.288^{*}$ & -0.720 & -1.720 \\
\hline$e d r_{i t}$ & -0.713 & $-4.656^{\star}$ & -2.323 & -1.291 & -1.342 & $-4.213^{*}$ & -2.474 & -2.238 \\
\hline$\Delta p h e h_{i t}$ & $-4.267^{\star}$ & $-3.141^{\star}$ & -2.287 & $-3.760^{\star}$ & $-3.846^{\star}$ & -2.874 & -2.079 & -2.758 \\
\hline$\Delta g d p h_{i t}$ & $-3.955^{\star}$ & $-3.535^{\star}$ & -2.471 & -1.521 & -2.299 & -1.586 & -1.559 & -0.949 \\
\hline$\Delta \operatorname{lexp}_{i t}$ & $-5.205^{\star}$ & -0.048 & $-3.424^{*}$ & -2.641 & $-4.373^{\star}$ & -1.888 & -2.207 & -2.172 \\
\hline$\Delta y d r_{i t}$ & -2.688 & $-3.783^{\star}$ & -2.217 & -1.709 & $-4.608^{\star}$ & $-3.782^{*}$ & $-3.692^{\star}$ & -1.909 \\
\hline$\Delta e d r_{i t}$ & $-4.037^{\star}$ & -2.696 & -2.826 & $-2.915^{\star}$ & -0.764 & $-4.381^{\star}$ & $-2.884^{\star}$ & -2.251 \\
\hline
\end{tabular}

Note: $\left.{ }^{*}\right)$ Rejection of the null hypothesis of independence at the threshold $\alpha=5 \%$.

public health spending by about $1.989 \%$ in WAEMU and $1.023 \%$ in CAEMC.

In the sense of Baltagi and Moscone [14], this reduction in the parameter took into account the effect of time reduces the dependence in cross section. However, it is noted that the addition of control variables leads to an increase in income elasticity values in the CAEMC (1.046) and the WAEMU (2.314).

In WAEMU, all variables that capture the "dependency ratio" are significant with a positive effect for $e d r_{i t}$ and a negative effect for $y d r_{i t}$. On the other hand, the $y d r_{i t}$ variable alone significantly and negatively influences public spending on health care in the CAEMC. This means that an increase in the youth dependency ratio of $1 \%$ would lead to a reduction in public health expenditure of about $3.09 \%$ in the WAEMU zone and about $4.69 \%$ in the CAEMC 
Table 4. Results of unit root tests CADF.

\begin{tabular}{|c|c|c|c|c|c|c|c|c|}
\hline & \multicolumn{8}{|c|}{ WAEMU } \\
\hline & \multicolumn{4}{|c|}{ pheh $_{\text {it }}$} & \multicolumn{4}{|c|}{$g d p h_{i t}$} \\
\hline & \multicolumn{4}{|c|}{ Number of delay } & \multicolumn{4}{|c|}{ Number of delay } \\
\hline & 0 & 1 & 2 & 3 & 0 & 1 & 2 & 3 \\
\hline Benin & -1.520 & -1.342 & -1.119 & -1.210 & -1.259 & -1.320 & -1.577 & -0.955 \\
\hline Burkina Faso & -1.734 & -1.587 & -1.280 & -1.732 & -1.487 & -1.682 & -2.081 & -1.449 \\
\hline Côte d'Ivoire & -1.803 & -1.770 & -1.350 & -2.066 & -1.457 & -1.885 & -1.699 & -0.665 \\
\hline Guinea-Bissau & -1.812 & -1.820 & -1.474 & -1.606 & -1.436 & -1.488 & -0.907 & -0.950 \\
\hline Mali & -1.730 & -1.455 & -1.178 & -1.617 & -1.722 & -1.853 & -2.280 & -1.488 \\
\hline Niger & -1.570 & -1.288 & -1.210 & -1.442 & -1.195 & -1.684 & -1.767 & -1.028 \\
\hline Senegal & -1.680 & -1.307 & -0.979 & -1.376 & -1.646 & -1.793 & -1.864 & -1.221 \\
\hline \multirow[t]{2}{*}{ Togo } & -1.539 & -1.407 & -1.379 & -1.759 & -1.351 & -1.695 & -1.368 & -0.860 \\
\hline & \multicolumn{8}{|c|}{ CAEMC } \\
\hline Cameroon & -2.191 & -1.954 & -1.626 & -1.750 & -1.404 & -1.756 & -0.969 & -1.535 \\
\hline Gabon & $-2.508^{\star}$ & -2.075 & -1.980 & -1.415 & -1.087 & -1.712 & -0.752 & -1.110 \\
\hline Equatoriale-Guinea & -1.732 & -1.517 & -1.604 & -1.365 & -1.037 & -1.278 & -0.862 & -0.775 \\
\hline Central African Republic & -2.130 & -2.033 & -1.906 & -1.160 & -0.734 & -1.428 & -0.597 & -0.321 \\
\hline Congo & -1.989 & -1.949 & -1.714 & -1.587 & -0.857 & -1.472 & -0.696 & -1.149 \\
\hline Chad & -2.150 & -2.033 & -2.052 & -1.821 & -0.668 & -0.996 & -0.745 & -0.645 \\
\hline
\end{tabular}

Note: $\left.{ }^{*}\right)$ Rejection of the null hypothesis of independence at the threshold $\alpha=5 \%$.

area, while a decrease in this would have adverse effects. This result seems counter-intuitive; however, it reflects the increase in the proportion of young people in the population creates specific needs for this age group and leads the state to reduce the share of GDP allocated to health to finance other social sectors such as education sector.

The CCEP estimator gives higher estimate of income elasticity in CAEMC area (1200) and the WAEMU (2900). This result is similar to previous studies on OECD countries [28] and in sub-Saharan Africa countries [29]. Moreover, these results show that the income elasticity is higher in the WAEMU zone than the CAEMC zone. For the $y d r_{i t}$ and $e d r_{i t}$ variables, they are not significant in the CAEMC zone, whereas in the WAEMU zone, these variables are significant.

\subsection{Short and LONG run Relationships}

The following Table 6 presents the CADF unit root tests on the residuals of the estimated equations. On one hand, the results of the CCEP regressions (Panel A) indicate that the residuals are stationary for order 2 (in the CAEMC) and 1 (in WAEMU) delays. On the other hand, the CCEP estimates (panel B) show that the residuals are stationary for $\mathrm{P}=2$ and 3 order delays only in the CAEMC. This implies the existence of a long-term relationship between public health 
Table 5. Determinants of public health expenditure.

\begin{tabular}{|c|c|c|c|c|c|c|c|c|}
\hline & \multicolumn{4}{|c|}{ WAEMU } & \multicolumn{4}{|c|}{ CAEMC } \\
\hline \multicolumn{9}{|c|}{ Panel A } \\
\hline & \multicolumn{2}{|c|}{ FE Estimate } & \multicolumn{2}{|c|}{ CCEP Estimate } & \multicolumn{2}{|c|}{ FE Estimate } & \multicolumn{2}{|c|}{ CCEP Estimate } \\
\hline & Coef. & Std. Err & Coef. & Std. Err & Coef. & Std. Err & Coef. & Std. Err \\
\hline$g d p h_{i t}$ & $1.989^{*}$ & 0.245 & $1.815^{*}$ & 0.256 & $1.023^{*}$ & 0.080 & $1.292^{*}$ & 0.090 \\
\hline \multicolumn{9}{|c|}{ CD statistiques ${ }^{* *}$} \\
\hline $\mathrm{CD}_{\mathrm{LM}}$ & $-2.52^{\star}$ & & $-3.14^{*}$ & & $-2.80^{\star}$ & & $-3.21^{*}$ & \\
\hline \multicolumn{9}{|l|}{ Panel B } \\
\hline pheh $_{i t}$ & $2.314^{*}$ & 0.307 & $2.900^{*}$ & 0.388 & $1.046^{*}$ & 0.109 & $1.200^{*}$ & 0.117 \\
\hline $\operatorname{lexp}_{i t}$ & 2.440 & 1.589 & 3.600 & 2.151 & 0.246 & 2.524 & -6.978 & 4.337 \\
\hline$y d r_{i t}$ & $-3.099^{*}$ & 1.142 & $-4.601^{\star}$ & 1.635 & $-4.697^{\star}$ & 1.698 & 2.456 & 2.245 \\
\hline$e d r_{i t}$ & $28.076^{\star}$ & 9.165 & $43.469^{*}$ & 17.433 & 14.965 & 14.350 & -12.007 & 11.821 \\
\hline \multicolumn{9}{|c|}{ CD statistiques ${ }^{* *}$} \\
\hline $\mathrm{CD}_{\mathrm{LM}}$ & $-2.07^{\star}$ & & $-2.80^{\star}$ & & $-2.89^{*}$ & & $-3.33^{*}$ & \\
\hline
\end{tabular}

Note: $\left(^{*}\right)$ Rejection of the null hypothesis of independence at the threshold $\alpha=5 \%$.

Table 6. Unit root in the test on residues.

\begin{tabular}{|c|c|c|c|c|c|c|c|c|}
\hline & \multicolumn{8}{|c|}{ CADF } \\
\hline & \multicolumn{4}{|c|}{ WAEMU } & \multicolumn{4}{|c|}{ CAEMC } \\
\hline & \multicolumn{4}{|c|}{ Number of delay } & \multicolumn{4}{|c|}{ Number of delay } \\
\hline & 0 & 1 & 2 & 3 & 0 & 1 & 2 & 3 \\
\hline \multicolumn{9}{|c|}{ PANEL A } \\
\hline$\hat{u}_{i t}(\mathrm{FE})$ & -1.729 & -1.634 & -1.320 & -1.229 & -2.078 & -1.643 & -1.268 & -1.899 \\
\hline$\hat{u}_{i t}(\mathrm{CCEP})$ & -2.144 & $-2.446^{\star}$ & -1.162 & -0.811 & -2.021 & -2.265 & $-3.592^{\star}$ & -2.298 \\
\hline \multicolumn{9}{|c|}{ PANEL B } \\
\hline$\hat{u}_{i t}(\mathrm{FE})$ & -1.822 & -1.756 & -1.257 & -1.748 & -2.205 & -1.957 & -1.561 & -1.663 \\
\hline$\hat{u}_{i t}(\mathrm{CCEP})$ & -1.703 & -1.499 & -0.911 & -0.832 & -2.279 & $-2.659^{*}$ & $-2.458^{\star}$ & -1.847 \\
\hline
\end{tabular}

Note: $\left(^{\star}\right)$ Rejection of the null hypothesis of independence at the threshold $\alpha=5 \%$.

expenditure and income WAEMU countries.

At the CAEMC area, this reflects the existence of a long-term relationship between the two variables. On the other hand, for the regressions (FE), the assumption of the existence of a unit root on the residues cannot be rejected in the two unions for the delays $\mathrm{P}=0,1,2,3$. Consequently, there is an important difference between the CCEP and FE estimators.

The coefficient of $p h e h_{t-1}-\hat{\beta}^{\prime} X_{i, t-1}$ measures the speed of adjustment of public health expenditure to a deviation of the long-run equilibrium relationship between expenditure and its determinants. This coefficient is negative and significant in panels A and B (Table 7). As a result, short-term changes in life 
Table 7. Error correction models (CCEP Method).

\begin{tabular}{|c|c|c|c|c|c|c|c|c|}
\hline & \multicolumn{4}{|c|}{ WAEMU } & \multicolumn{4}{|c|}{ CAEMC } \\
\hline & \multicolumn{2}{|c|}{ Panel A } & \multicolumn{2}{|c|}{ Panel B } & \multicolumn{2}{|c|}{ Panel A } & \multicolumn{2}{|c|}{ Panel B } \\
\hline & Coeff. & Std. Err. & Coeff. & Std. Err. & Coeff. & Std. Err. & Coeff. & Std. Err. \\
\hline pheh $_{t-1}-\hat{\beta}^{\prime} X_{i, t-1}$ & $-0.507^{\star}$ & 0.098 & $-0.615^{*}$ & 0.101 & $-0.356^{*}$ & $0.169^{*}$ & $-0.446^{*}$ & 0.186 \\
\hline$\Delta$ pheh $_{i, t-1}$ & $0.206^{*}$ & 0.086 & $0.184^{*}$ & 0.081 & -0.046 & 0.100 & -0.071 & 0.108 \\
\hline$g d p h_{i t}$ & $1.026^{*}$ & 0.404 & $1.011^{\star}$ & 0.389 & $0.899^{*}$ & 0.198 & $0.934^{\star}$ & 0.226 \\
\hline$\Delta \operatorname{lexp}_{i t}$ & & & 3.073 & 4.500 & & & 23.611 & 17.179 \\
\hline$y d r_{i t}$ & & & 0.690 & 7.525 & & & 3.163 & 12.702 \\
\hline$e d r_{i t}$ & & & 82.546 & 62.387 & & & -74.419 & 158.412 \\
\hline \multicolumn{9}{|l|}{ CD statistiques ${ }^{* *}$} \\
\hline $\mathrm{CD}_{\mathrm{LM}}$ & $4.92^{\star}$ & & $5.11^{\star}$ & & $2.85^{*}$ & & $2.72^{*}$ & \\
\hline
\end{tabular}

Note: $\left.{ }^{*}\right)$ indique que les coefficients sont significatifs au seuil $\alpha=5 \%$.

expectancy at birth and dependency rates do not appear to have significant effects on public health expenditure in both WAEMU and the CAEMC. On the other hand, in the short term, changes in income have a significant and positive impact on public health spending.

\section{Conclusions}

In this study that analyzes the effects of economic growth on health public spending, in WAEMU and CAEMC, we have reexamined the inter-relationships that could exist between these two economic aggregates. The panel data techniques have helped analyze "stationarity" and co-integration between these outcomes on the 1995-2013. The results show that the estimated income elasticity in the two economic areas is higher than one. Moreover, the tabulated income elasticity is higher in the WAEMU zone than the one in the CAEMC: this means on one hand that the effort that is required to the WAEMU countries to adjust the level of their health public expenditures to their GDP's evolution is bigger than that of the CEMAC countries, but on the other hand, that the CAEMC's economy seems more performing than the WAEMU's one.

Nevertheless, the "youth dependence rate" negatively influences health government spending in the WAEMU area as well as in the CEMAC one. Meaning, in these countries, a rise in youth percentage leads Governments to reducing the GDP share allocated to health and investing it in other competing sectors such as education. To avoid this situation, governments should engage in private public partnerships (PPPs). This would allow governments to better invest in the health sector.

In all, this study confirms indeed the expedience to create conditions which are favorable to a supportable economic growth and a better allocation of available resources in order to increase health service productivity. 
This study gives major results however it has some limitations: 1 ) it does not address the causality between public health spending and economic growth; 2) the duration of the study (19 years) is relatively short because of the unavailability of data on public health expenditure in all 14 countries before 1995; 3) the study deals cross-sectional dependence according to the approach by the structure factors but does not address the spatial approach.

\section{References}

[1] World Health Organization (2000) Health Systems: Improving Performance. The World Health Report, Geneva, 1-19.

[2] Tang, C.F. (2009) An Examination of the Government Spending and Economic Growth Nexus for Malaysia Using the Leveraged Bootstrap Simulation Approach. Global Economic Review, 38, 215-227. https://doi.org/10.1080/12265080902903266

[3] Hartwig, J. (2008) What Drives Health Care Expenditure? Baumol's Model of Unbalanced Growth Revisited. Journal of Health Economics, 27, 603-623. https://doi.org/10.1016/j.jhealeco.2007.05.006

[4] Newhouse, J. (1977) Medical Care Expenditure: A Cross-National Survey. Journal of Human Resources, 12, 67-79. https://doi.org/10.2307/145602

[5] Leu, R.E. (1986) Public and Private Health Services: Complementarities and Conflicts. In: Culyer, A.J. and Jonsson, B., Eds., Blackwell, Oxford, 41-63.

[6] Hitiris, T. and Posnett, J. (1992) The Determinants and Effects of Health Expenditure in Developed Countries. Journal of Health Economics, 11, 173-181. https://doi.org/10.1016/0167-6296(92)90033-W

[7] Hansen, P. and King, A. (1996) The Determinants of Health Care Expenditure: A Cointegration Approach. Journal of Health Economics, 15, 127-137. https://doi.org/10.1016/0167-6296(95)00017-8

[8] Barro, R.J. (1991) Economic Growth in a Cross Section of Countries. Quarterly Journal of Economics, 106, 407-443. https://doi.org/10.2307/2937943

[9] Barro, R. J. and Sala-I-Martin, X. (1992) Convergence. Journal of Political Econo$m y$, 100, 223-251. https://doi.org/10.1086/261816

[10] Fogel, R.W. (1994) Economic Growth, Population Theory and Physiology: The Bearing of Long-Term Processes on the Making of Economic Policy. The American Economic Review, 84, 369-395. https://doi.org/10.3386/w4638

[11] Barro, R.J. (1998) Determinants of Economic Growth: A Cross-County Empirical Study. Journal of Comparative Economics, 26, 822-824. https://doi.org/10.1006/jcec.1998.1532

[12] Tiehi, T.N. (2013) Antenatal Care in Côte d'Ivoire: An Empirical Investigation. World Journal of Social Sciences, 3,144-157.

[13] World Bank (2012) World Development Report. World Bank Group, Washington DC.

[14] Baltagi, B.H. and Moscone, F. (2010) Health Care Expenditure and Income in the OECD Reconsidered: Evidence from Panel Data? Economic Modelling, 27, 804-811. https://doi.org/10.1016/j.econmod.2009.12.001

[15] Revelli, F. (2006) Performance Rating and Yardstick Competition in Social Service Provision. Journal of Public Economics, 90, 459-475.

https://doi.org/10.1016/j.jpubeco.2005.07.006 
[16] Moscone, F. and Knapp, M. (2005) Exploring the Spatial Pattern of Mental Health Expenditure. Journal of Mental Health Policy and Economics, 8, 205-217.

[17] Moscone, F., Knapp, M. and Tosetti, E. (2007) Mental Health Expenditure in England: A Spatial Panel Approach. Journal of Health Economics, 26, 842-864. https://doi.org/10.1016/j.jhealeco.2006.12.008

[18] Lorant, V., Thomas, I., Deliege, D. and Tonglet, R. (2001) Deprivation and Mortality: The Implications of Spatial Autocorrelation for Health Resources Allocation. Social Science and Medicine, 53, 1711-1719. https://doi.org/10.1016/S0277-9536(00)00456-1

[19] Thouez, J., Emard, J.-F., Beaupre, M., Latreille, J. and Ghadirian, P. (1997) Space Time Analysis of the Incidence of Cancer in Certain Sites of Quebec. Canadian Journal of Public Health, 88, 48-55.

[20] Alexander, F. (1993) Viruses, Clusters and Clustering of Childhood Leukemia. European. Journal of Cancer, 29, 24-43.

[21] Gatrell, A. and Whiteleg, J. (1993) Incidence of Childhood Cancer in Preston and South Ribble? Environmental Epidemiology Research Unit, Lancaster University Research Report.

[22] Hsiao, C. (2000) Comparing the Performance of Two Indices for Spatial Model Selection: Application to Two Mortality Data, Statistics in Medicine, 19, 1915-1930. https://doi.org/10.1002/1097-0258(20000730)19:14<1915::AID-SIM503>3.0.CO;2$\underline{\mathrm{M}}$

[23] Pesaran, M.H. (2007) A Simple Panel Unit Root Test in the Presence of Cross-Section Dependence. Journal of Applied Econometrics, 22, 265-312. https://doi.org/10.1002/jae.951

[24] Audibert, M., Mathonnat, J., Brun, J.-F. and Carrere, C. (2002) Dette extérieure et situation socio-politique: Quel rôle dans les dépenses publiques de santé dans les pays en développement. Document de Travail, CERDI, Etudes et documents, E2002, 20.

[25] Chudik, A., Pesaran, M. and Tosetti, E. (2011) Weak and Strong Cross Section Dependence and Estimation of Large Panels. Econometrics Journal, 14, C45-C90. https://doi.org/10.1111/j.1368-423X.2010.00330.x

[26] Im, K.S., Pesaran, M.H. and Shin, Y. (2003) Testing for Unit Roots in Heterogeneous Panels. Journal of Econometrics, 115, 53-74. https://doi.org/10.1016/S0304-4076(03)00092-7

[27] Breitung, J. (2000) The Local Power of Some Unit Root Tests for Panel Data, In Baltagi, B., Ed., Nonstationary Panels, Panel Cointegration, and Dynamic Panels, Advances in Econometrics, JAI, Amsterdam, 15, 161-178. https://doi.org/10.1016/S0731-9053(00)15006-6

[28] Jaunky, V.C. and Khadaroo, A.J. (2008) Health Care Expenditure and GDP: An African Perspective. Applied Econometrics and International Development, 8, 131-146.

[29] Getzen, T.E. (2000) Health Care Is an Individual Necessity and a National Luxury: Applying Multilevel Decision Models to the Analysis of Health Care Expenditures. Journal of Health Economics, 19, 259-270. https://doi.org/10.1016/S0167-6296(99)00032-6 